J. Dairy Sci. 96:3671-3681

http://dx.doi.org/10.3168/jds.2012-6182

(C) American Dairy Science Association ${ }^{\circledR}, 2013$.

\title{
The effect of somatic cell count data adjustment and interpretation, as outlined in European Union legislation, on herd eligibility to supply raw milk for processing of dairy products
}

\author{
S. J. More, ${ }^{*} \dagger^{1}$ T. A. Clegg, ${ }^{*}$ P. J. Lynch, $\ddagger$ and L. O’Grady $\dagger$ \\ ${ }^{*}$ Centre for Veterinary Epidemiology and Risk Analysis, UCD School of Veterinary Medicine, University College Dublin, Belfield, Dublin 4, Ireland \\ †UCD School of Veterinary Medicine, University College Dublin, Belfield, Dublin 4, Ireland \\ ‡Department of Agriculture, Food and the Marine, Kildare St., Dublin 2, Ireland
}

\begin{abstract}
Somatic cell count (SCC) limits are a key component of national and international regulation for milk quality. As yet, very limited work has been published on SCC regulatory standards, including on the effect of different approaches to SCC data adjustment and interpretation. This study examines the effect of SCC data adjustment and interpretation, as outlined in current European Union (EU) legislation, on herd eligibility to supply raw milk for processing of dairy products for human consumption, using Irish data for illustration. The study used Irish milk-recording data as a proxy for bulk tank SCC (BTSCC) data, to calculate an unadjusted monthly SCC value for each herd during each month of participation. Subsequently, 4 data adjustments were applied, as outlined in EU and national legislation: seasonal adjustment; 3-mo rolling geometric average, without accounting for a break in the supply; 3-mo rolling geometric average, after accounting for a break in the supply; and seasonal adjustment and 3-mo rolling geometric average combined, after accounting for a break in the supply. Analyses were conducted to examine the effect, during the period from 2004 to 2010, of data adjustment on the percentage of herds with herd SCC $>400,000$ cells $/ \mathrm{mL}$. In all, 4 interpretation scenarios, incorporating different data adjustment combinations, were used to estimate herd eligibility (compliant, under warning, or suspended, as defined by legislation) to supply raw milk for processing. The 4 methods of data adjustment each led to a sizable reduction $(6.7,5.0,5.3$, and 11.1 percentage points, respectively, compared with the unadjusted data) in the percentage of herds exceeding a herd SCC of 400,000 cells/mL. Herd eligibility varied by interpretation scenarios, in particular those incorporating seasonal adjustment. The study provides new perspectives on the effect of data adjustment on
\end{abstract}

Received September 21, 2012

Accepted February 27, 2013.

${ }^{1}$ Corresponding author: simon.more@ucd.ie herd SCC and of interpretation scenarios on herd eligibility. The results provide an illustrative, rather than definitive, picture of this effect, as national authorities use BTSCC data when determining herd eligibility, whereas this study was conducted using milk-recording data as a proxy. Some aspects of the primary EU legislation are unclear, which may lead to differences in interpretation and application. The potential impact of data adjustment and milk purchaser pricing on farmlevel mastitis control in Ireland is considered.

Key words: data adjustment, somatic cell count, European Union legislation, Ireland

\section{INTRODUCTION}

Somatic cell count is an important measure of milk quality, reflecting the health status of the mammary gland and the risk of nonphysiological changes to milk composition. High SCC milk is associated with reduced milk yield (Hand et al., 2012; Boland et al., 2013), as well as increased costs associated with treatment, culling, and changes in milk quality. During processing, high SCC milk adversely affects cheese production, as a result of reduced curd firmness, decreased milk yield, increased fat and casein loss in whey, and compromised sensory quality (Munro et al., 1984; Politis and NgKwai-Hang, 1988). High SCC milk also affects the yield of milk protein concentrate and reduces the shelf life of pasteurized liquid milk (Ma et al., 2000; More, 2009). Processors generally use differential raw milk pricing, a series of penalties and bonuses to supplying farmers, to meet the market demand for low SCC milk. Somatic cell count limits are also a key component of national and international regulation for milk quality (More, 2009). These regulatory SCC limits can be considered the lowest quality acceptable, noting that lower SCC limits are generally achieved as a result of processordriven differential milk pricing.

Different regulatory SCC limits have been set by different countries (within the United States, different standards also apply in different states), which creates 
difficulties if a country wishes to export to another country with more restrictive limits (Norman et al., 2000, 2011). The European Union (EU) regulatory SCC limit has progressively been adopted as the international export standard in many dairy countries (Brightling et al., 2009; More, 2009). The United States has a national penalty limit of 750,000 cells/mL for local consumption (US Food and Drug Administration, 2011), but recently introduced a European Union Health Certification Program, specifying an SCC threshold of 400,000 cells/mL for companies exporting products into the EU (USDA Agricultural Marketing Service, 2011).

Within the EU, the eligibility to supply raw milk for processing of dairy products for human consumption is governed by Regulations 853/2004 (European Community, 2004a) and 854/2004 (European Community, 2004b) using measurements of raw bulk tank milk SCC (BTSCC) to determine eligibility. Data gathered from an individual herd are subject to adjustment before an assessment is made of herd eligibility to supply. For each month, all the results from BTSCC testing are combined with the results from the previous 2 mo and geometrically averaged to create a 3 -mo rolling geometric average, to even out monthly SCC fluctuations. At the end of each month, the herd's 3-mo rolling geometric average is compared with the regulatory SCC limit (400,000 cells $/ \mathrm{mL})$ and with additional rules as outlined in EU Regulation 854/2004. A further 3-mo period is needed to determine herd eligibility to supply raw milk for processing. Within Ireland, seasonal adjustments and an additional methodology for a break in supply are applied to the raw BTSCC, as provided for in EU Regulation 853/2004. The Food and Veterinary Office carries out audits to monitor compliance with relevant regulations.

Substantial work, over many years, has addressed concerns with SCC measurement. Work toward a reference system for SCC in milk was published in 2008 (Baumgartner, 2008; Orlandini et al., 2008), and progress has been made to address concerns relating to laboratory variability and other factors affecting data quality, including sampling methods, sample transport, and storage (Hillerton et al., 2004). Within the EU, national reference laboratories play an important role in verifying compliance with relevant Community legislation (European Community, 2004c). As yet, however, published work on SCC regulatory standards has been very limited, particularly in regard to the effect of different approaches to SCC data adjustment and interpretation. Norman et al. (2011) recently investigated the consequences of alternative BTSCC standards on the eligibility of herds in the United States to supply milk for human consumption.
In the current study, the effect of SCC data adjustment and interpretation was examined, as outlined in current EU legislation, on herd eligibility to supply raw milk for processing of dairy product for human consumption. The results provide an illustrative, rather than definitive, picture of this effect, as national authorities use BTSCC data when determining herd eligibility, whereas this study was conducted using milk-recording data as a proxy. The potential influence of these data adjustments with regard to on-farm mastitis control is discussed.

\section{MATERIALS AND METHODS}

\section{European and Irish Legislation}

As required under EU Regulation 853/2004, the SCC in raw milk must not exceed 400,000 cells/mL (based on a rolling geometric average over a 3-mo period, with at least one sample per month; European Community, 2004a). When raw milk fails to comply, the competent authority must be notified and the food business operator shall take measures to correct the situation. Further, EU Regulation 854/2004 (European Community, 2004b) states that, once the 3-mo geometric average exceeds 400,000 cells/mL, the supplier then has 3 mo in which to reduce the 3 -mo geometric average to below the 400,000 cells/mL limit. In practice, the supplier will receive warnings from the milk purchaser during this period of recovery and of eventual rejection, if necessary, if the milk remains noncompliant at the end of the 3 -mo recovery period. In addition, Ireland applies an adjusted calculation method to milk collected during the winter months to account for seasonal variations in production levels, as provided for in EU Regulation 853/2004 (European Community, 2004a).

In Ireland, therefore, several adjustments are made to herd SCC data, as outlined in EU legislation (either directly or following Irish interpretation), as follows:

(1) Seasonal adjustment: "To take account of the seasonality of milk production in Ireland and to ensure the SCC is not unduly distorted on this account, a formula has been devised for the recording of results for the winter months from November to February inclusive. The formula is based on the national monthly production pattern for the winter period before that during which it is used. A co-efficient is obtained by dividing the national milk production level recorded each month from November to February by $50 \%$ of the average monthly production level for each of the 6 mo from April to September inclusive" [DAFM circular of 14 October 2011, De- 
partment of Agriculture, Food and the Marine, 2011; in reference to Regulation (EC) No. 853 of 2004, Regulation (EC) No. 854 of 2004, and Regulation (EC) No. 2074 of 2005 (European Community, 2005) as amended by Regulation (EC) No. 1664 of 2006 (European Community, 2006), and Statutory Instrument No. 432 of 2009; Irish Government, 2009]. The coefficient is calculated by the national Department of Agriculture, Food and the Marine (DAFM, previously known as the Department of Agriculture, Fisheries and Food) and the milk purchasers are notified of the coefficient in October each year.

(2) A 3-mo rolling geometric average: "Food business operators must ... ensure that raw milk meets the following criteria: Somatic cell count (per $\mathrm{mL}$ ) (of) $\leq 400,000$ [Rolling geometric average over a 3 -mo period, with at least one sample per month ...]" (EU Regulation 853/2004; European Community, 2004a). "While a minimum of one test must be carried out each month, it is permissible to carry out a greater number, provided all the results are taken into account in calculating the geometric average" (DAFM circular of 14 October 2011; DAFM, 2011). The calculation of 3-mo rolling geometric average is affected by a "break in the supply," as follows: "Where a supplier ceases production for a period of at least one calendar month at or about the end of the herd's lactation, then when the supply recommences the calculation of the geometric average for the purposes of determining compliance with the SCC standards laid down in the Regulations should start afresh; there should be no regard to the results of testing carried out before the break in production" (DAFM circular of 14 October 2011; DAFM, 2011).

(3) The 3-mo recovery period: "If the food business operator has not corrected the situation within 3 mo of first notifying the competent authority of non-compliance with the criteria with regard to ... somatic cell count, delivery of raw milk from the production holding is to be suspended ... This suspension ... (is) to remain in place until the food business operator has proved that the raw milk again complies with the criteria." (EU Regulation 854/2004; European Community, 2004b).

As illustrated in Figure 1, and based on the abovementioned legislation, herds can be classified as compliant (group 1), under warning (group 2), or suspended (group 3). Herds in groups 1 and 2 are able to supply milk for processing, whereas herds in group 3 are not.
Group 1 includes all herds with a 3-mo rolling geometric average $\leq 400,000$ cells $/ \mathrm{mL}$, after applying seasonal adjustment and accounting for a break in the supply, if relevant. In addition, following any break in supply, each herd, by default, is compliant during the first 2 mo of supply, as the 3-mo rolling geometric average is not yet calculable.

The following illustrates events that occur when the herd 3-mo rolling geometric average exceeds 400,000 cells/mL:

- Month 1: The 3-mo rolling geometric average is calculated at the end of each month; therefore, herds are considered compliant (a group 1 herd) throughout the first month that the 3 -mo rolling geometric average exceeds 400,000 cells/mL.

- Months 2-4: A herd is under warning (a group 2 herd) for a maximum of 3 mo (from mo 2 to 4) where the 3-mo rolling geometric average continues to exceed 400,000 cells/mL.

- Month 5: A herd is suspended (a group 3 herd) from the start of mo 5 where the 3-mo rolling geometric average continues to exceed 400,000 cells $/ \mathrm{mL}$.

Figure 1 illustrates all potential recovery pathways to compliance for group 2 and 3 herds.

\section{The Study Data}

In Ireland, as elsewhere, BTSCC is measured at regular intervals from supplying farms, based on samples taken at the point of bulk tank milk collection. These data are held by individual milk processors, but were not nationally available at the time of this study. For this reason, milk-recording data have been used as a proxy for bulk tank data.

Information about the collection of milk-recording data has been presented previously (More et al., 2012). Briefly, all available milk-recording data from 2003 to 2010, inclusive, from the Irish Cattle Breeding Federation (ICBF; Bandon, Co. Cork, Ireland) were obtained; ICBF is responsible for national collation of milk-recording data in Ireland. The data set included a single SCC value for each herd at each milk-recording, the number of cows sampled, and the total volume of milk recorded. Each cow's SCC at the recording had been weighted by her respective yield so the mean would reflect each herd's BTSCC more accurately. Preliminary data screening was conducted to identify and remove all duplicate (invalid) records (arbitrarily, duplicate onfarm milk-recordings fewer than $21 \mathrm{~d}$ apart). Recordings with fewer than 10 cows, with more than $50 \%$ of samples unreadable, or with a SCC $<20,000$ cells $/ \mathrm{mL}$ 


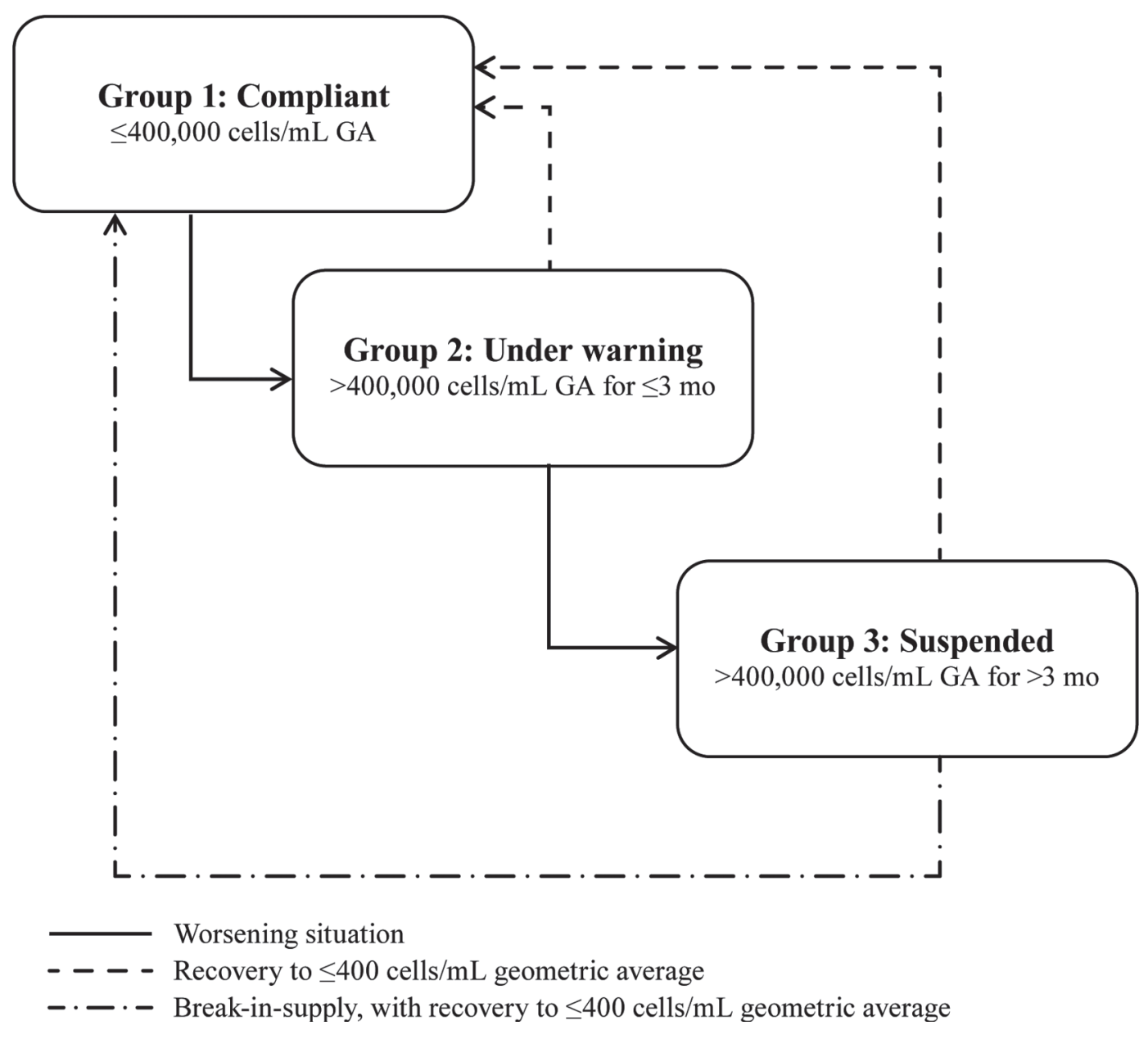

Figure 1. Grouping of herds according to European Union (EU) and Irish legislation as compliant (group 1 herds), under warning (group 2 ), or suspended (group 3), and potential pathways between each herd grouping. Herds in groups 1 and 2 are able to supply milk for processing, whereas herds in group 3 are not. $\mathrm{GA}=3$-mo rolling geometric average.

were also removed. Finally, for any one year, only those herds with data from at least 10 milk-recordings were retained. Therefore, in the final unadjusted data set, a specific herd could be represented in some years (a study herd-year; with 10 or more milk-recordings) but not represented in other years because fewer than 10 milk-recordings were conducted.

For each study herd-year, the months of supply were identified, and a single SCC value ("unadjusted monthly SCC value") was determined during each of these months, as follows: (1) if only one milk-recording was conducted in any month, the SCC value at this recording was used; (2) if more than one milk-recording was conducted in a calendar month, the geometric average SCC value was calculated; and (3) if a gap of 1 calendar month occurred between milk-recordings, the geometric average of the 2 monthly records on either side of the missing month was used to impute an SCC value for the missing month.
Therefore, a final data set was available for further investigation, subsequently termed "the unadjusted data," comprising a single (or missing) herd SCC value for each study herd during each month of enrollment. For each year during 2003 to 2010, unadjusted data were available on different sets of study herds. Fewer herds participated in milk recording during 2003 compared with later years. Therefore, although analyses were conducted throughout the whole period (2003-2010), only the results during 2004-2010 are reported.

\section{Effect of Data Adjustment}

Outcomes of Interest. Analyses were conducted to examine the effect of different data adjustments, and associated interpretation scenarios, on 2 outcomes of interest: (1) the percentage of herds with herd SCC $>400,000$ cells $/ \mathrm{mL}$, and (2) the percentage of herds eligible "to supply raw milk for processing of dairy prod- 
ucts for human consumption" (subsequently termed "herds eligible"), based on herd classification (compliant, under warning, or suspended). The first of these outcomes was considered when evaluating 4 different data adjustments and the second when evaluating 4 different interpretation scenarios. Data manipulation and analyses were conducted using SAS version 9.1 (SAS Institute Inc., Cary, NC) and graphs were created using Microsoft Excel 2007 (Microsoft Corp., Redmond, WA).

Percentage of Herds with Herd SCC >400,000 cells $/ \boldsymbol{m L}$. In total, the effect of 4 different data adjustments was investigated as outlined below. For each adjustment, the percentage of herd SCC values that exceeded 400,000 cells/mL each month during 2004-2010 was calculated. The average difference, each month and each year, in the percentage of herds exceeding 400,000 cells/mL was also calculated by comparing each data adjustment to the unadjusted data. The denominator was consistent across all data adjustments, but varied year to year, based on the total number of study herds present in the unadjusted data. Therefore, in some situations, herds were present in the denominator but were not eligible for inclusion in the numerator (e.g., herds during the first 2 mo of supply following the start of the first lactation and any break in supply, when the 3-mo rolling geometric average was not yet calculable).

The 4 data adjustments were as follows:

(1) Seasonal adjustment: The data were modified following blanket application of the seasonality formula, as used routinely in Ireland (Table 1). In 2006-2007, for example, during relevant months, the unadjusted SCC data on all supplying farms were multiplied by the monthly coefficients of 0.75 (November 2006), 0.47 (December 2006), 0.38 (January 2007), and 0.64 (February 2007).

(2) A 3-mo rolling geometric average, without accounting for a break in the supply: The 3-mo rolling geometric average was calculated using the unadjusted monthly herd-level SCC value from the current and 2 previous months of supply. The 3-mo rolling geometric mean was calculated as long as the gap between the unadjusted monthly SCC values was $<5$ mo. To illustrate, if unadjusted monthly SCC values were available from a farm for all months except December and January, the 3-mo rolling geometric average for November was calculated using unadjusted monthly SCC values from September, October, and November; for February using data from October, November, and February; for March using data from November, February, and March.

(3) A 3-mo rolling geometric average, after accounting for a break in the supply: The 3-mo rolling geometric average was calculated using the unadjusted monthly SCC value from the current and 2 previous months. In herds with a break in the supply (i.e., a gap of $>1$ mo occurred between unadjusted monthly SCC values), the geometric average calculations ended at the last month before this break, and restarted once supply was restored. Using this approach, the 3-mo rolling geometric average was not calculable during the first 2 mo following a break in the supply.

(4) Seasonal adjustment and 3-mo rolling geometric average, after accounting for a break in the supply: a combination of the first and third data adjustments above.

Percentage of Herds Compliant, Under Warning, and Suspended. In total, the effects of 4 interpretation scenarios were investigated, incorporating different data adjustment combinations, as outlined below. For each scenario and for each month during 2004-2010, the percentage of herds in each of the 3 herd classifications was calculated. The 4 interpretation scenarios were as follows. Scenario 1: no seasonal adjustment, 3-mo rolling geometric average (without accounting for a break in the supply); scenario 2: no seasonal adjustment, 3-mo rolling geometric average (after accounting for a break in the supply); scenario

Table 1. Adjustment coefficient ${ }^{1}$ applied to raw milk in Ireland during winter 2003-2004 to 2010-2011

\begin{tabular}{lcccc}
\hline Year & November & December & January & February \\
\hline $2003-2004$ & 0.75 & 0.48 & 0.37 & 0.62 \\
$2004-2005$ & 0.86 & 0.52 & 0.38 & 0.63 \\
$2005-2006$ & 0.78 & 0.48 & 0.38 & 0.64 \\
$2006-2007$ & 0.75 & 0.47 & 0.38 & 0.64 \\
$2007-2008$ & 0.81 & 0.52 & 0.38 & 0.63 \\
$2008-2009$ & 0.92 & 0.53 & 0.39 & 0.67 \\
$2009-2010$ & 0.83 & 0.57 & 0.44 & 0.73 \\
$2010-2011$ & 0.81 & 0.52 & 0.41 & 0.72 \\
\hline
\end{tabular}

${ }^{1}$ The coefficient was obtained by dividing the national milk production level recorded each month during the period by $50 \%$ of the average monthly value of the national milk production recorded from April to September before the start of the period in question. 


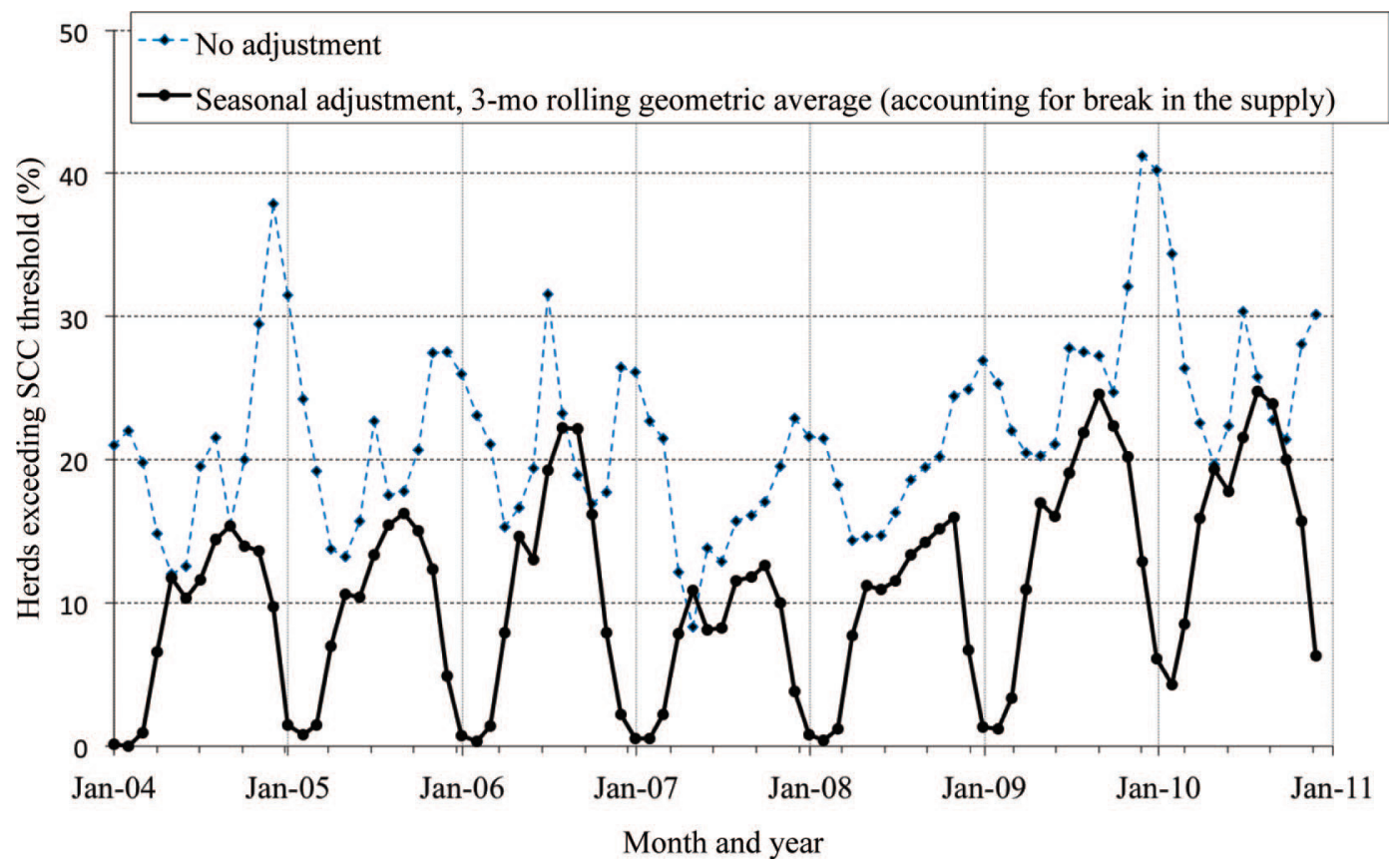

Figure 2. The percentage of Irish dairy herds with herd SCC exceeding 400,000 cells/mL, based on SCC data collected from milk-recording herds during 2004 to 2010. These data are presented with no adjustment or following the application of the seasonal adjustment and the 3-mo rolling geometric average (after accounting for a break in the supply). In herds with a break in supply (i.e., a gap of $>1$ mo between unadjusted monthly SCC values), the geometric average calculations ended at the last month before this break and restarted once supply was restored. Analysis was restricted to herds with at least 10 milk-recordings during a calendar year. Color version available in the online PDF.

3: seasonal adjustment, 3-mo rolling geometric average (without accounting for a break in the supply); and scenario 4: seasonal adjustment, 3-mo rolling geometric average (after accounting for a break in the supply).

\section{RESULTS}

\section{Percentage of Herds with Herd SCC $>400,000 \mathrm{cells} / \mathrm{mL}$}

The percentage of herds with herd SCC $>400,000$ cells/mL, with no adjustment and with seasonal adjustment and the 3-mo rolling geometric average (accounting for a break in the supply) is presented in Figure 2. With no adjustment, the maximum percentage of herds with an SCC >400,000 cells $/ \mathrm{mL}$ was $41.2 \%$ in December 2009 and the minimum was $8.3 \%$ in May 2007. When adjustments were applied, the maximum decreased to 24.8\%, which occurred in August 2010 and the minimum decreased to 0\% in February 2004. Further details of other comparisons are presented in the online data supplement [Figures S1 (no adjustment vs. seasonal adjustment), S2 (no adjustment vs. 3-mo rolling geometric average without accounting for a break in the supply), and S3 (no adjustment vs. 3-mo rolling geometric average accounting for a break in the supply); http://www.journalofdairyscience.org/). The average monthly difference in the percentage of herds exceed- ing the SCC threshold is presented in Table 2, based on a comparison of each adjustment (or adjustment combination) with the unadjusted data. The average yearly difference in the percentage of herds exceeding the SCC threshold is presented in Table 3, based on a comparison of each adjustment (or adjustment combination) with the unadjusted data.

The 4 methods of data adjustment each led to a sizable reduction $(6.7,5.0,5.3$, and 11.1 percentage points for scenarios 1 to 4, respectively, compared with the unadjusted data; Table 2), consistent over time (Table 3 ), in the percentage of herds exceeding a herd SCC of 400,000 cells/mL. Seasonal adjustment was influential during November to February, leading to a maximum monthly reduction of 26.4 percentage points in January, compared with unadjusted data (Table 2, Figure 2). The effect of 3-mo geometric average was marginally greater after accounting for a break in supply, as compared with not accounting for the break in supply, but only during the months of February to April (Table 2; Figures S2 and S3; http://www.journalofdairyscience.org/).

\section{Percentage of Herds Compliant, Under Warning, and Suspended}

The percentage of Irish dairy herds during 2004-2010 that were compliant, under warning, or suspended for each of the 4 interpretation scenarios is presented in 
Table 2. Average differences in the percentage of herds exceeding a herd SCC of 400,000 cells $/ \mathrm{mL}$, by month, based on a comparison of each adjustment (or adjustment combination) with the unadjusted data ${ }^{1}$

\begin{tabular}{|c|c|c|c|c|}
\hline Month & SA & $\begin{array}{c}\text { GA } \\
\text { (without break) }\end{array}$ & $\begin{array}{c}\text { GA } \\
\text { (with break) }\end{array}$ & $\begin{array}{c}\text { GA } \\
\text { (with break) and SA }\end{array}$ \\
\hline January & -26.4 & -9.2 & -9.2 & -26.1 \\
\hline February & -17.5 & -7.6 & -8.6 & -23.7 \\
\hline March & 0.0 & -3.5 & -4.8 & -18.4 \\
\hline April & 0.0 & -0.8 & -1.2 & -7.1 \\
\hline May & 0.0 & -1.3 & -1.3 & -1.3 \\
\hline June & 0.0 & -4.7 & -4.7 & -4.7 \\
\hline July & 0.0 & -8.1 & -8.1 & -8.1 \\
\hline August & 0.0 & -3.7 & -3.7 & -3.7 \\
\hline September & 0.0 & -1.3 & -1.3 & -1.3 \\
\hline October & 0.0 & -3.7 & -3.7 & -3.7 \\
\hline November & -11.0 & -7.7 & -7.7 & -11.9 \\
\hline December & -25.8 & -9.0 & -9.0 & -23.5 \\
\hline Total & -6.7 & -5.0 & -5.3 & -11.1 \\
\hline
\end{tabular}

Figure 3, Figure S4 (http://www.journalofdairyscience. org/), Figure 4, and Figure S5 (http://www.journalof dairyscience.org/), respectively. The results of scenarios 1 and 2 were similar: an approximately equal number of herds were suspended or under warning (in total, a median of 11.9\%; Figure 3), little evidence was found of seasonal trends, and an increase was observed in the percentage of herds under warning or suspended during the last 2 yr of the study (Figure 3 and Figure S4). The results of scenarios 3 and 4 were also similar, but markedly different from those of scenarios 1 and 2 : fewer herds were under warning or suspended (median of $7.8 \%$ suspended or under warning; Figure 4) and very marked seasonality was observed, with almost no herds under warning or suspended during the early months of each year (Figure 4 and Figure S5).

\section{DISCUSSION}

This work was conducted to examine the effect of data adjustment and interpretation, as outlined in EU and Irish legislation, on herd eligibility to supply raw milk for processing. National authorities invariably use BTSCC data when determining herd eligibility to supply raw milk for processing, whereas this study was conducted using milk-recording data as a proxy. For this reason, the results provide an illustrative, rather than a definitive, picture of the impact of data adjustment and interpretation.

The 4 methods of data adjustment each led to sizable reductions (Table 2), consistent during each year of the study (Table 3), in the percentage of herds exceeding a herd SCC of 400,000 cells/mL. Differences were observed, however, in the time of year when each adjustment method was most influential (Table 2). Seasonal adjustment only had an effect during December to March, which simply reflects the timing when seasonal adjustment is applied in Ireland. For the 3-mo rolling geometric average, the reduction was greatest in November to February and in July. In Ireland, herd SCC is at its highest during the winter months in spring-calving herds (between 2004 and 2010, the highest median herd SCC value was 370,000 cells $/ \mathrm{mL}$ in December 2009 and lowest median value was 206,000 cells/mL in May 2007; More et al., 2012). The use of the 3-mo rolling geometric average has the effect, as intended (Norman et al., 2011), of smoothing the data and reducing the influence of a high SCC value. The smaller increase in July varied somewhat over time (from a low of -4.6 percentage points in 2007 to -12.3 percentage points in 2006), and was probably a reflection of high SCC in association with the start of calving in autumn-calving herds. This latter effect has been diluted, because most Irish herds are spring-calving (More et al., 2012). The effect of 3-mo geometric average was marginally greater after accounting for a break in supply (compared with not accounting for a break in supply) during the months of February to April. This effect is coincident with the start of calving in Irish spring-calving dairy herds (Table 2, Figures S2 and S3; http://www.journalofdairyscience.org/) because the former will include several months (specifically the 2 mo following a break in the supply) during which the 3-mo geometric average is not calculable, leading to fewer months where herd SCC had the potential to exceed 400,000 cells/mL).

The combined use of seasonal adjustment and 3-mo rolling geometric average (after accounting for a break 


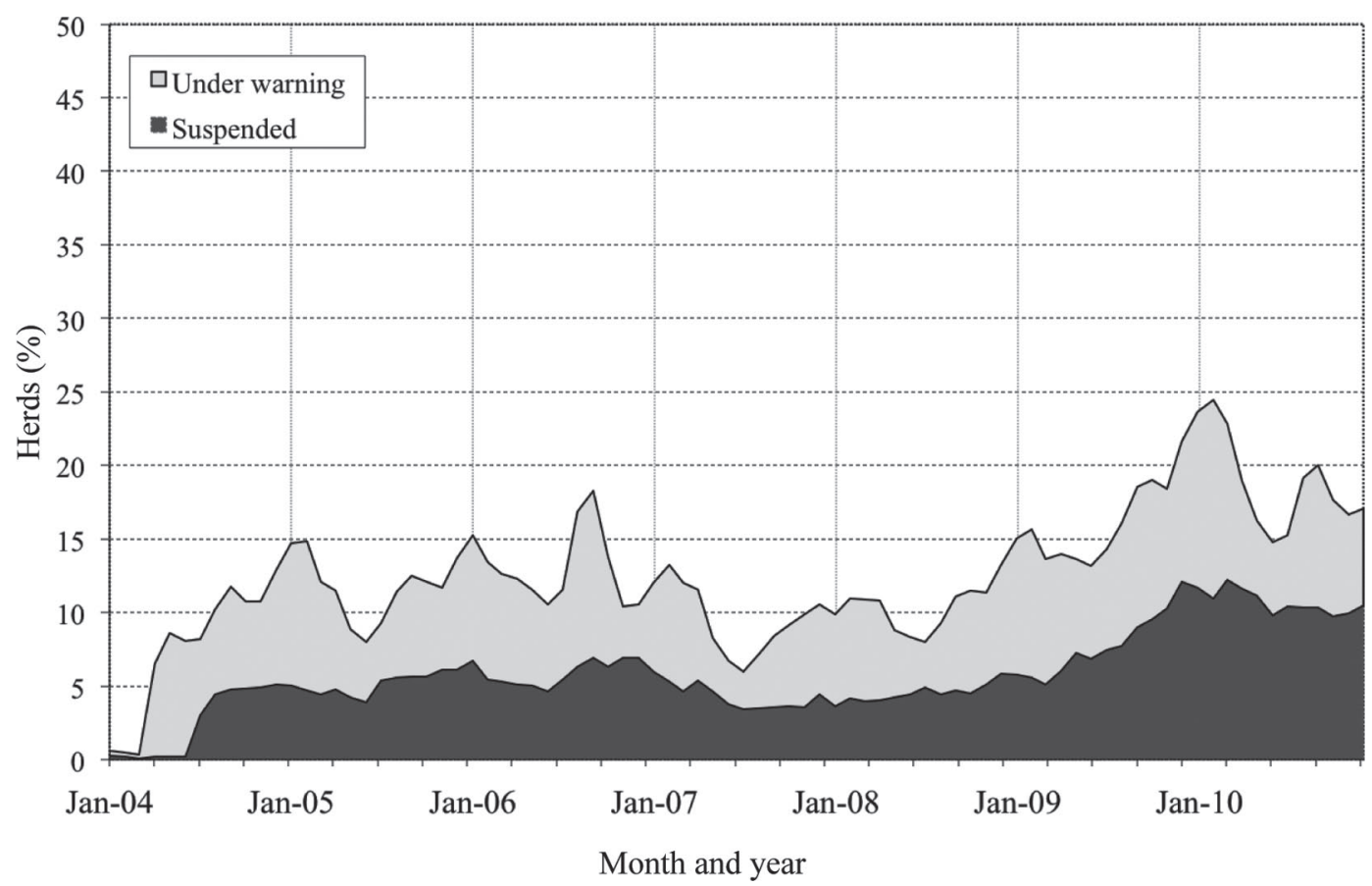

Figure 3. The percentage of Irish dairy herds during 2004-2010, with at least 10 recordings each year, that were compliant or under warning, given interpretation scenario 1 (no seasonal adjustment, 3-mo rolling geometric average without accounting for a break in the supply). The 3-mo rolling geometric mean was calculated as long as the gap between the unadjusted monthly SCC values was $<5$ mo.

in supply), as currently applied in Ireland, leads to an average reduction of 11.1 percentage points in the percentage of herds exceeding a herd SCC of 400,000 cells/mL (Tables 2 and 3 ). Note that this effect is not directly additive (i.e., a reduction of 6.7 percentage points for seasonal adjustment plus a reduction of 5.3 percentage points for 3-mo rolling geometric average (after accounting for a break in supply) does not equal -11.1 percentage points) because seasonal adjustment is applied before the 3-mo rolling geometric average. As a consequence, the final adjustment is affected by the effect of any seasonal adjustment in both the month of interest and any relevant preceding months.
Herd eligibility to supply is substantially affected by the rules used for data interpretation, with seasonal adjustment being by far the most influential (Figures 3 and 4, Figures S4 and S5, http://www. journalofdairyscience.org/). Without seasonal adjustment (Figure 3 and Figure S4), 12\% of herds, on average, could be under warning or suspended. However, when seasonal adjustment is applied (Figure 4 and Figure S5), a dramatic seasonal pattern emerges: in mid-summer, the results are very similar to that achieved without seasonal adjustment, whereas throughout the winter months, few herds are under warning or suspended.

Table 3. Average differences in the percentage of herds exceeding the SCC threshold, by year, based on a comparison of each adjustment (or adjustment combination) with the unadjusted data ${ }^{1}$

\begin{tabular}{|c|c|c|c|c|}
\hline Month & SA & $\begin{array}{c}\text { GA } \\
\text { (without break) }\end{array}$ & $\begin{array}{c}\text { GA } \\
\text { (with break) }\end{array}$ & $\begin{array}{c}\mathrm{GA} \\
\text { (with break) and SA }\end{array}$ \\
\hline 2004 & -6.6 & -8.8 & -8.8 & -11.5 \\
\hline 2005 & -7.3 & -5.0 & -5.2 & -11.8 \\
\hline 2006 & -6.5 & -4.0 & -4.3 & -10.7 \\
\hline 2007 & -6.2 & -4.2 & -4.5 & -10.1 \\
\hline 2008 & -5.2 & -4.8 & -5.0 & -10.0 \\
\hline 2009 & -7.3 & -5.3 & -5.5 & -12.2 \\
\hline 2010 & -8.0 & -3.4 & -3.8 & -11.7 \\
\hline Total & -6.7 & -5.0 & -5.3 & -11.1 \\
\hline
\end{tabular}

${ }^{1} \mathrm{SA}=$ seasonal adjustment; GA (without break) $=3$-mo rolling geometric average without accounting for a break in the supply (GA was calculated as long as the gap between the unadjusted monthly SCC values was $<5 \mathrm{mo}$ ); GA (with break) $=3$-mo rolling geometric average after accounting for a break in the supply. In herds with a break in the supply (i.e., if a gap of $>1$ mo occurred between unadjusted monthly SCC values), the geometric average calculations ended in the last month before this break and restarted once supply was restored. 


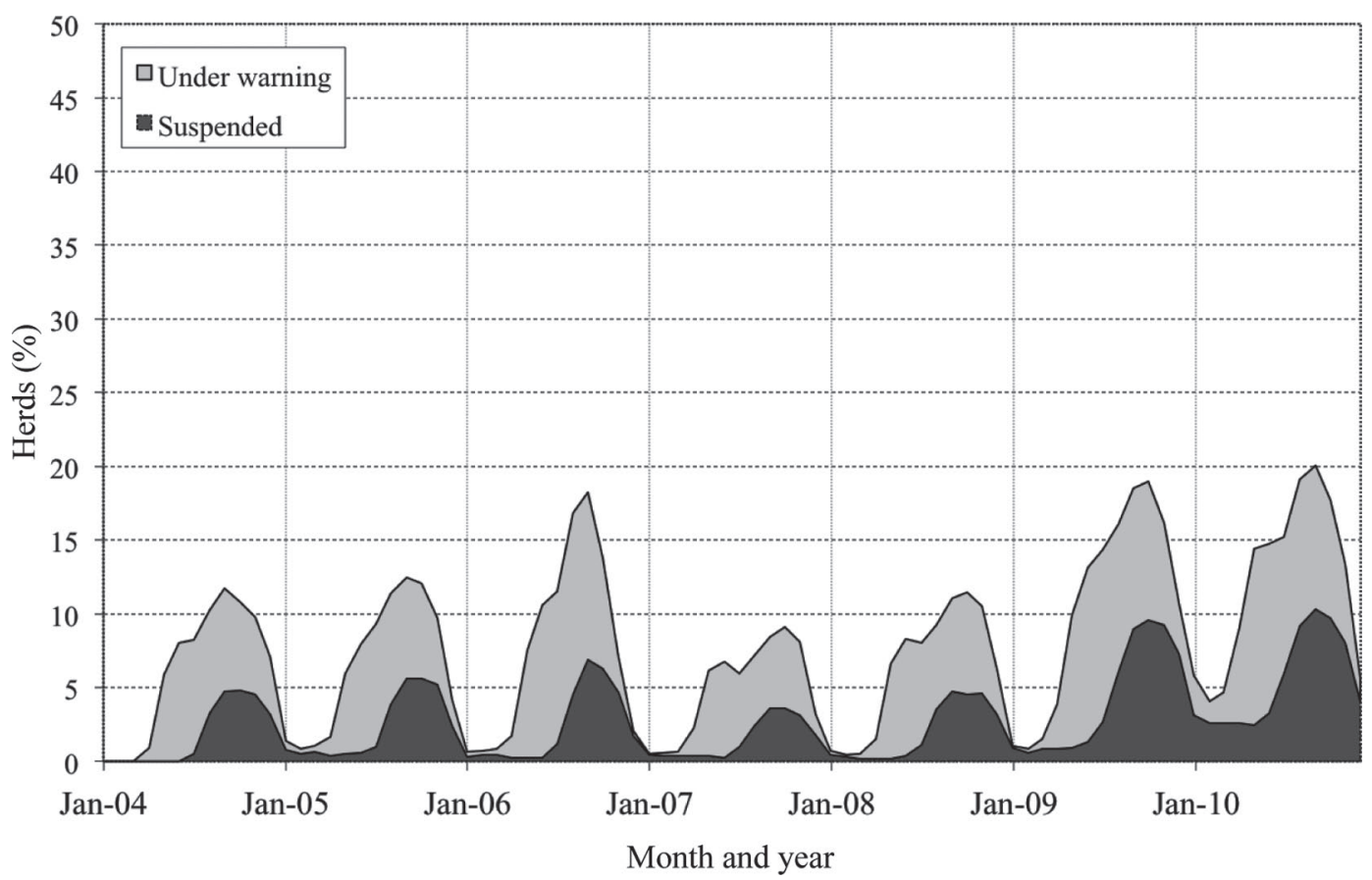

Figure 4. The percentage of herds during 2004-2010, with at least 10 recordings each year, that were compliant or under warning, given interpretation scenario 3 (seasonal adjustment and 3-mo rolling geometric average without accounting for a break in the supply). The 3-mo rolling geometric mean was calculated as long as the gap between the unadjusted monthly SCC values was $<5$ mo.

These data highlight the substantial increase in SCC in the national herd each winter. A seasonal increase in SCC has also been reported elsewhere. In the United Kingdom, there is no evidence that a greater new infection rate is associated with an observed increase in BTSCC during summer (Green et al., 2006). In the United States, SCC is also generally highest in summer, coincident with an increased incidence of clinical mastitis and attributed to the effect of environmental conditions (Norman et al., 2000). The reason for the winter SCC increase in Ireland has yet to be clarified. It is coincident with reduced milk volumes, reflecting the seasonal nature of milk production in Ireland. However, pathology, rather than physiology, might be the greater contributor to this observed SCC increase in Ireland. In a recent paper, no evidence was found in support of a dilution effect (a decrease in SCC with increasing milk yield) in Irish dairy cattle (Boland et al., 2013). Further, it is known that udder health is a concern on several Irish dairy farms, with Staphylococcus aureus being the most frequently isolated organism (More et al., 2012). It is recognized that infection status is the single most important factor influencing SCC (Reneau, 1986; Laevens et al., 1997), with stage of lactation, age, season, and various stresses on SCC each being less influential (Reneau, 1986), particularly if the gland is uninfected (Harmon, 1994; Laevens et al., 1997). Further research is warranted to determine the relative importance of factors influencing the winter SCC increase in Ireland.

In this study, milk-recorded data were used as a proxy for BTSCC data, specifically because the latter were not available. As mentioned previously, the results therefore provide an illustrative, rather than a definitive, picture of the effect of data adjustment and interpretation. A similar approach was used by Norman et al. (2011), where milk-recording data were used to investigate the impact of alternative SCC standards in the United States. In Ireland, milk-recorded data are available from approximately 6,000 herds (More et al., 2012), representing 33\% of the national herd (Irish Cattle Breeding Federation, 2012). The milk-recording SCC data may not necessarily provide an accurate reflection of national BTSCC data. On farms with udder health concerns, farmers may withhold cows with high SCC from the bulk tank to comply with milk quality regulations and avoid financial penalties (Norman et al., 2011; More et al., 2012). In these circumstances, BTSCC will be lower than "the unadjusted monthly SCC value" derived from milk-recorded data. The use of milk-recording data is unlikely to affect the broad study results, noting that our interest relates to the relative, rather than the absolute, effect of data adjustment and interpretation on herd eligibility. 
Some aspects of the primary EU legislation are unclear, which may lead to differences in interpretation and application. Several examples are given here. One example relates to SCC calculations for seasonally calving herds. The legislative guidelines specify the use of a 3-mo rolling geometric average, thereby smoothing out short-term SCC fluctuations (Norman et al., 2011). This approach is straightforward in herds with year-round calving; however, no detail is provided in the legislation of the approach to be taken in situations with a break in supply. In this research, an interpretation (adjustment for a break in supply), as currently applied in Ireland, is presented, although there may be others. As highlighted previously, the effect of 3 -mo geometric average is marginally greater after accounting for a break in supply, compared with not accounting for it, but only during the months of February to April (Table 2). A second example concerns the number of milk samples tested each month. As defined in EU Regulation 853/2004 (European Community, 2004a), SCC testing must be conducted on "at least one sample each month," but no further detail is given. Clarification is provided in the DAFM circular of 14 October 2011 (DAFM, 2011), which states that all test results are to be taken into account in computing the geometric average. Using this approach, however, it would be permissible to dilute the effect of a single high SCC result by conducting further SCC testing during the same calendar month, but with high SCC cows identified and removed from later testing points.

Within the EU, separate legislative streams relate to food safety and to animal health and welfare. The SCC limits, which are the focus of this research, are based on food safety legislation, with a primary concern to ensure that collected milk is of a minimum quality standard. It is problematic, however, that the SCC limit of $\leq 400,000$ cells $/ \mathrm{mL}$ is well above the generally recognized target of $<200,000$ cells $/ \mathrm{mL}$ for bulk tank SCC in herds where mastitis is under control (Smith et al., 2001). In other words, the food safety legislation is at odds with optimal on-farm animal health and welfare. As a consequence, significant animal health and welfare problems can persist on farms despite compliance with the SCC limits for collection. In addition, the existing data adjustments, as currently practiced throughout the EU, have the potential to widen the gap between 200,000 cells/mL (the SCC level associated with good udder health) and the allowable SCC limit as regulated under food safety legislation, thereby allowing an increased number of farmers, compared with situations without data adjustment, to supply milk while mastitis problems still persist in their herds. These regulated SCC limits, therefore, play a limited role to improve on-farm animal health and welfare. In any subsequent legislative review, these concerns should be considered.

The current legislation is written in the form of input-based standards, which are prescriptive, focusing on actions that need to be taken (Cameron, 2012). Input-based standards do not necessarily ensure the desired results. In the event of legislative review, thought could be given to the development of appropriate output-based standards for mastitis control, focusing on what is to be achieved rather than what is to be done (Cameron, 2012). Recent examples of work toward output-based standards are available from other areas of animal health (e.g., More et al., 2009).

In 2011, CellCheck, a national initiative (based on Countdown Downunder; Brightling et al., 2009) to improve the control of mastitis (More et al., 2011; Animal Health Ireland, 2012), was launched in Ireland. This initiative aims to provide the infrastructure (knowledge, technical skill, and information technology) to support improved udder health on farms. Farmer engagement with the initiative will be central to its success. Regulatory or industry penalty limits play a significant part in the motivation of dairy farmer to address udder health issues (Valeeva et al., 2007), and differential payments on SCC are common practice in many countries. Within Ireland, differential payments vary among processors, and the use of bonuses for low SCC milk is not universally applied. An opportunity exists in Ireland for greater use of processor-driven differential milk pricing to support the achievement of low SCC and sustainable milk quality improvement.

\section{CONCLUSIONS}

These results highlight the effect of methods currently applied within the EU (and specifically in Ireland) and the particular influence of seasonal adjustment in increasing herd eligibility in Ireland during the winter months. The study provides new perspective on data adjustment and interpretation, the relative effect of each on herd eligibility to supply raw milk for processing, and ultimately the lack of impact of the current legislation to greatly influence mastitis control at the farm level. These issues are of concern and should be addressed, given the role now played by the EU legislation on SCC limits in international best practices in milk quality. The points raised in the discussion should be considered as part of any review of the legislation. Currently, separate legislative streams relate to product quality and to animal health and welfare. Harmonizing the relevant legislation to address product quality in conjunction with animal health and welfare issues together and using performance-based targets reflect- 
ing adequate mastitis control would have the benefits of improving animal health and welfare and increasing production efficiency at the farm or industry level, ultimately benefiting the consumer.

\section{ACKNOWLEDGMENTS}

Assistance from Seán Coughlan (Irish Cattle Breeding Federation, Bandon, Co. Cork) for providing the data is gratefully acknowledged.

\section{REFERENCES}

Animal Health Ireland. 2012. CellCheck: Introduction. Accessed Sep. 21, 2012. http://www.animalhealthireland.ie/page.php?id=29.

Baumgartner, C. 2008. Architecture of reference systems, status quo of somatic cell counting and concept for the implementation of a reference system for somatic cell counting. Bull. Int. Dairy Fed. $427: 2-14$.

Boland, F., L. O'Grady, and S. J. More. 2013. Investigating a dilution effect between somatic cell count and milk yield and estimating milk production losses in Irish dairy cattle. J. Dairy Sci. 96:14771484. http://dx.doi.org/10.3168/jds.2012-6025.

Brightling, P., R. Dyson, A. Hope, and J. Penry. 2009. A national programme for mastitis control in Australia: Countdown Downunder. Ir. Vet. J. 62(Suppl. 4):S52-58.

Cameron, A. R. 2012. The consequences of risk-based surveillance: Developing output-based standards for surveillance to demonstrate freedom from disease. Prev. Vet. Med. 105:280-286.

DAFM (Department of Agriculture, Food and the Marine). 2011. To each milk purchaser or users of own milk supplies, re: sampling and testing of milk for TBC and SCC as required under Regulation (EC) No. 853 of 2004. Circular of 14 October 2011. Department of Agriculture, Food and the Marine, Dublin, Ireland.

European Community. 2004a. Regulation (EC) No 853/2004 of the European Parliament and of the Council of 29 April 2004 laying down specific hygiene rules for food of animal origin. Off. J. L139:55-205. (including subsequent corrigenda and amendments).

European Community. 2004b. Regulation (EC) No 854/2004 of the European Parliament and of the Council of 29 April 2004 laying down specific rules for the organisation of official controls on products of animal origin intended for human consumption. Off. J. L139:206320. (including subsequent corrigenda and amendments).

European Community. 2004c. Regulation (EC) No 882/2004 of the European Parliament and of the Council of 29 April 2004 on official controls to ensure the verification of compliance with feed and food law, animal health and animal welfare rules. Off. J. L191:159. (including subsequent amendments).

European Community. 2005. Commission Regulation (EC) No. 2074/2005 of 5 December 2005 laying down implementing measures for certain products under Regulation (EC) No 853/2004 of the European Parliament and of the Council and for the organisation of official controls under Regulation (EC) No 854/2004 of the European Parliament and of the Council and Regulation (EC) No 882/2004 of the European Parliament and of the Council, derogating from Regulation (EC) No 852/2004 of the European Parliament and of the Council and amending Regulations (EC) No 853/2004 and (EC) No 854/2004. Off. J. L338:27-59.

European Community. 2006. Commission Regulation (EC) No 1664/2006 of 6 November 2006 amending Regulation (EC) No $2074 / 2005$ as regards implementing measures for certain products of animal origin intended for human consumption and repealing certain implementing measures. Off. J. L320:27-59.

Green, M. J., A. J. Bradley, H. Newton, and W. J. Browne. 2006. Seasonal variation of bulk milk somatic cell counts in UK dairy herds: Investigations of the summer rise. Prev. Vet. Med. 74:293-308.

Hand, K. J., A. Godkin, and D. F. Kelton. 2012. Milk production and somatic cell counts: A cow-level analysis. J. Dairy Sci. 95:13581362.
Harmon, R. J. 1994. Physiology of mastitis and factors affecting somatic cell counts. J. Dairy Sci. 77:2103-2112.

Hillerton, J. E., E. A. Berry, M. B. Gravenor, and N. Middleton. 2004. Errors associated with milk cell counting. Vet. Rec. 155:445-448.

Irish Cattle Breeding Federation. 2012. Milk-recording as a decision support system for the commercial farmer-Ireland developments. Accessed Sep. 21, 2012. http://www.icbf.com/services/milk recording/overview/index.php.

Irish Government. 2009. European Communities (Food and Feed Hygiene) Regulations 2009. (S.I. No. 432 of 2009). Accessed Sep. 21, 2012. http://www.irishstatutebook.ie/2009/en/si/0432.html

Laevens, H., H. Deluyker, Y. H. Schukken, L. De Meulemeester, R. Vandermeersch, E. De Muêlenaere, and A. De Kruif. 1997. Influence of parity and stage of lactation on the somatic cell count in bacteriologically negative dairy cows. J. Dairy Sci. 80:3219-3226.

Ma, Y., C. Ryan, D. M. Barbano, D. M. Galton, M. A. Rudan, and K. J. Boor. 2000. Effects of somatic cell count on quality and shelf-life of pasteurized fluid milk. J. Dairy Sci. 83:264-274.

More, S. 2009. Global trends in milk quality: Implications for the Irish dairy industry. Ir. Vet. J. 62(Suppl. 4):S5-14.

More, S. J., A. R. Cameron, M. Greiner, R. S. Clifton-Hadley, S. Correia Rodeia, D. Bakker, M. D. Salman, J. M. Sharp, F. De Massis, A. Aranaz, M. B. Boniotti, A. Gaffuri, P. Have, D. Verloo, M. Woodfood, and M. Weirup. 2009. Defining output-based standards to achieve and maintain TB freedom in farmed deer, with reference to member states of the European Union. Prev. Vet. Med. 90:254-267.

More, S. J., T. A. Clegg, and L. O'Grady. 2012. Insights into udder health and intramammary antibiotic usage on Irish dairy farms during 2003-2010. Ir. Vet. J. 65:7. http://dx.doi.org/10.1186/20460481-65-7.

More, S. J., M. L. Doherty, L. Downey, K. McKenzie, C. Devitt, and J. O'Flaherty. 2011. Animal Health Ireland: Providing national leadership and coordination of non-regulatory animal health issues in Ireland. Rev. Sci. Tech. 30:715-723.

Munro, G. L., P. A. Grieve, and B. J. Kitchen. 1984. Effects of mastitis on milk yield, milk composition, processing properties and yield and quality of milk products. Aust. J. Dairy Technol. 39:7-16.

Norman, H. D., J. E. Lombard, J. R. Wright, C. A. Kopral, J. M. Rodriguez, and R. H. Miller. 2011. Consequences of alternative standards for bulk tank somatic cell count of dairy herds in the United States. J. Dairy Sci. 94:6243-6256.

Norman, H. D., R. H. Miller, J. R. Wright, and G. R. Wiggins. 2000. Herd and state means for somatic cell count from Dairy Herd Improvement. J. Dairy Sci. 83:2782-2788.

Orlandini, S., L. Lattanzi, A. M. Toscano, and U. Paggi. 2008. Interlaboratory collaborative study on the reference method for somatic cell counting in cow's milk: ISO 13366-1|IDF 148-1. Bull. Int. Dairy Fed. 427:15-21.

Politis, I., and K. F. Ng-Kwai-Hang. 1988. Effects of somatic cell counts and milk composition on cheese composition and coagulating properties of milk. J. Dairy Sci. 71:1711-1719.

Reneau, J. K. 1986. Effective use of dairy herd improvement somatic cell counts in mastitis control. J. Dairy Sci. 69:1708-1720.

Smith, K. L., J. E. Hillerton, and R. J. Harmon. 2001. Guidelines on normal and abnormal raw milk based on somatic cell counts and signs of clinical mastitis. National Mastitis Council, Madison, KY. Accessed Jan. 14, 2013. http://nmconline.org/docs/abnmilk.pdf.

US Food and Drug Administration. 2011. Grade 'A' Pasteurized Milk Ordinance, 2011 revision. Accessed Jan. 14, 2013. http://www.fda. gov/downloads/Food/FoodSafety/Product-SpecificInformation/ MilkSafety/NationalConferenceonInterstateMilkShipments NCIMSModelDocuments/UCM291757.pdf.

USDA Agricultural Marketing Service. 2011. European Union Health Certification Program. Notice to the Industry, November 22, 2011. Accessed Sep. 21, 2012. http://www.ams.usda.gov/AMSv1.0/ getfile?dDocName=STELPRD3636640.

Valeeva, N. I., T. J. G. M. Lam, and H. Hogeveen. 2007. Motivation of dairy farmers to improve mastitis management. J. Dairy Sci. 90:4466-4477. 